\title{
Recognising and mitigating the risk of altitude-related illness
}

The recent tragic and widely publicised death of South African (SA) celebrity Gugu Zulu on Mount Kilimanjaro has drawn significant public interest and speculation about the risks of high-altitude trekking and climbing. ${ }^{[1]}$ It has also demonstrated numerous myths and misconceptions with regard to safe high-altitude ascents among not only the lay public, but also medical professionals. Kilimanjaro is of particular relevance, as it has a very high incidence of altitude-related illnesses. ${ }^{[2-5]}$ Regardless of the details of the Zulu tragedy, a great number of southern Africans undertake treks on Kilimanjaro each year. We have a responsibility to improve understanding and access to medically sound advice for prospective adventurers, and to encourage tour operators to plan and market adventure activities that mitigate the risks to participants.

While the proportional composition of the atmosphere remains remarkably consistent, ambient pressure decreases logarithmically with ascent, causing a corresponding decrease in the partial pressure of oxygen $\left(\mathrm{PO}_{2}\right)^{[6]}$ The physiological effects of altitude are predominantly due to the resultant hypoxia and hypobaria. High altitude is defined as $>1500 \mathrm{~m}$ above sea level, where the physiological effects of altitude may first be consistently observed, but pathological consequences are very rare. ${ }^{[7]}$ At this level, the alveolar partial pressure of oxygen $\left(\mathrm{P}_{\mathrm{A}} \mathrm{O}_{2}\right)$ is $\sim 10 \mathrm{kPa}$, compared with the sea level value of $13 \mathrm{kPa}$. It is worth noting that large areas of SA, including the extensive metropolitan areas in Gauteng, therefore qualify as highaltitude areas. Above $3500 \mathrm{~m}$ is referred to as very high altitude, above which immediate compensatory mechanisms no longer suffice, acclimatisation over time is required, and the incidence of acute high-altitude illness (HAI) due to rapid ascent increases dramatically. This can include the syndrome complex known as acute mountain sickness (AMS), or the more severe and life-threatening conditions, high-altitude cerebral or pulmonary oedema (HACE or HAPE). While uncommon, cases have occurred in the Drakensberg mountains (authors' experience). Altitudes $>5500 \mathrm{~m}$ are referred to as extreme altitudes. Exposure to these levels without gradual acclimatisation will almost certainly result in severe illness. ${ }^{[8]}$ At the top of Kilimanjaro (5 $895 \mathrm{~m}$, barometric pressure $\sim 47 \mathrm{kPa}$ ), atmospheric air has a $\mathrm{PO}_{2}$ of only $9.4 \mathrm{kPa}$ and the alveolar gas equation predicts that even with maximal hyperventilation and hypocarbia, the $\mathrm{P}_{\mathrm{A}} \mathrm{O}_{2}$ can only approach $6 \mathrm{kPa}$ (Fig. 1). This is less than half of the sea level value, despite adequate acclimatisation. Values $<3 \mathrm{kPa}$ have been recorded in healthy climbers on Everest. ${ }^{[9]}$

The only reliable preventive measure to combat HAI is a slow rate of ascent to altitude, allowing adequate time for physiological acclimatisation. While most healthy individuals can acclimatise up to $5500 \mathrm{~m}$, HAI can be induced in any individual if the rate of ascent is sufficiently rapid. Contrary to common beliefs, youth, physical and aerobic fitness, gender and previous ascent to high altitudes offer no protection. ${ }^{[7]}$ Medications such as acetazolamide (Diamox) may hasten acclimatisation, but still require a suitably slow ascent profile to have a protective effect. ${ }^{[3]}$

Numerous evidence- and consensus-based guidelines for safe ascent rates and acclimatisation exist, ${ }^{[8,10,11]}$ but are not uniformly applied. ${ }^{[5]}$ Typically, above $3500 \mathrm{~m}$, an increase in sleeping altitude of $\leq 500 \mathrm{~m} /$ day is recommended, with a rest day for each 3 - 4 days' climb. The old climber's adage 'climb high, sleep low' may confer an advantage, but this has not been proven in the literature. While most of the world's highest peaks lie deep within wilderness areas and require a lengthy trek to reach (and therefore time for acclimatisation), Kilimanjaro is a particularly important exception. As the world's highest free-standing mountain, it allows rapid ascent from the surrounding lowlands $(<700 \mathrm{~m})$. Conversely, the absence of requirement for technical climbing skills to gain the $5895 \mathrm{~m}$ summit, combined with the allure of one of the Seven Summits, draws $>30000$ aspirant summiteers every year - many of whom have never before experienced extreme altitudes. While the trekking distances required make reaching the summit in 3 - 4 days easily achievable, acclimatising to nearly $6 \mathrm{~km}$ above sea level cannot occur in such a short time. Itineraries of 4 - 5 days have rates of AMS $>75 \%,{ }^{[4]}$ while

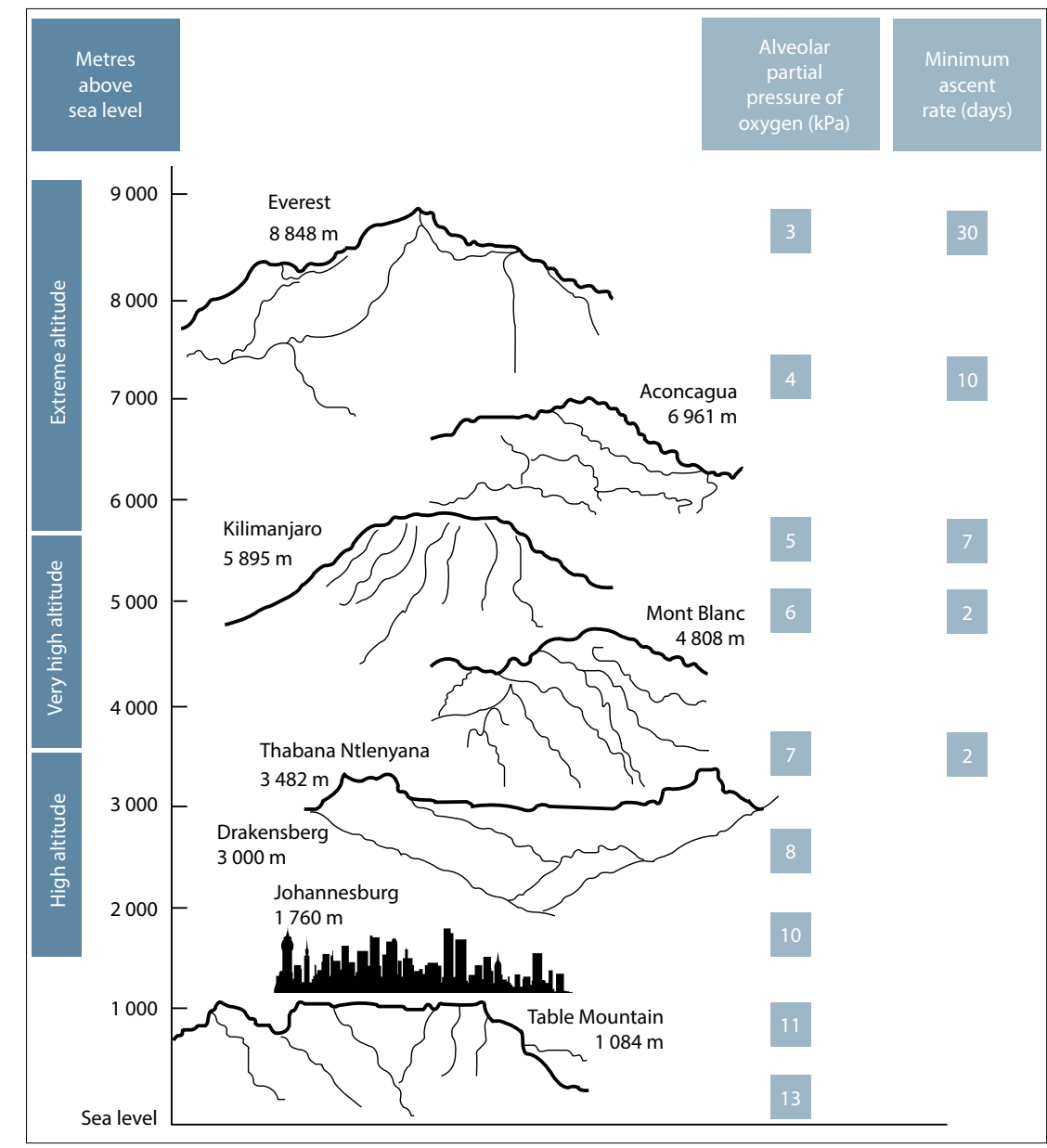

Fig. 1. Relative heights of well-known African and international peaks in comparison to Kilimanjaro, with approximate $P_{A} \mathrm{O}_{2}$ values and minimum duration of safe ascents (drawing by the authors, $P_{A} \mathrm{O}_{2}$ values calculated). 
HACE incidence has been reported as $18 \%{ }^{[2]}$ Indeed, consensus statements in the wilderness medical literature indicate that ascents of $<7$ days carry very high risks. ${ }^{[10]}$ In contrast to this lies the commercial imperative: every day on Kilimanjaro incurs additional guiding, porter, camping, national park and rescue fees, all of which create a perverse incentive to hurry, imposed by the almighty dollar. This is further compounded by the pressure placed on the guides by companies and climbers alike, for whom summit success is paramount.

It is important to recognise that AMS symptoms are nonspecific (headache, nausea, vomiting, gastrointestinal upset, fatigue and poor sleep) and mimic common conditions such as influenza. ${ }^{[12]}$ HAI is very rare below $2500 \mathrm{~m}$, but any new symptoms occurring after ascent above $3500 \mathrm{~m}$ should be presumed to be altitude related until proven otherwise. Mild AMS can be managed by temporarily halting ascent, simple analgesia and hydration. Moderate to severe AMS (or any evidence of HACE or HAPE) should result in immediate descent until symptoms subside. Adherence to these simple guidelines should minimise the risk of an altitude-induced death.

Mountaineers on expeditions on remote peaks traditionally make provision for the risk of altitude illness by allowing time for acclimatisation, and carrying suitable supplies for treatment if such illness should occur. While medication and descent are the mainstay of altitude illness, supportive therapy with supplemental oxygen and portable hyperbaric chambers can be lifesaving, especially in cases where descent is delayed or impossible owing to weather or logistical difficulties. Despite the relative accessibility of Kilimanjaro, and while many tour operators claim to offer their services, the varying level of medical skills and number of groups spread across the mountain make availability questionable. Reliance on helicopter rescue in this region, even without the limits of altitude, weather, and darkness, is inadvisable.

Historically, mountaineering expeditions have been medically supported by recreational mountaineers who are doctors and who may have very varied backgrounds and medical skills. In recent times, however, the importance of providing high-quality, evidence-based practice in wilderness, remote and austere settings has driven the development and rapid growth of the disciplines and formal education in wilderness, expedition and extreme medicine. ${ }^{[13]}$ Examples include the Fellowship of the Academy of Wilderness Medicine (FAWM) ${ }^{[14]}$ under the auspices of the Wilderness Medical Society (WMS), and the Diploma in Mountain Medicine (DiMM),${ }^{[15]}$ under the auspices of the International Climbing and Mountaineering Federation (UIAA). As practice has evolved, published standards for the education, skills and proficiencies of expedition medics have emerged. ${ }^{[16,17]}$ Until very recently, these educational opportunities have not been available in SA. Currently, however, internationally accredited training courses are being offered, and a Wilderness and Expedition Medicine Society of Southern Africa (WEMSSA) has been formed.

Owing to the accessibility and popularity of climbing Kilimanjaro and other African peaks, practitioners should recognise the significant risks of very high altitude ascents and refer participants to accepted guidelines and expedition or altitude experts. Doctors wishing to serve as expedition medics should undertake formal training and obtain experience in the field, whether their role is voluntary or for remuneration. Large or specialist groups (such as charity events) are encouraged to request the services of an experienced and qualified expedition doctor, who can oversee planning, screening, equipment and the health of participants on the expedition. Finally, the medical fraternity should continue to advocate that individuals do not shy from the health benefits to be gained from the wilderness, while promoting adequate acclimatisation for high-altitude adventures and actively campaigning against itineraries placing participants at heightened risk.

\section{Ross Hofmeyr}

Department of Anaesthesia and Perioperative Medicine, Faculty of Health Sciences, University of Cape Town; and WildMedix, Cape Town, South Africa

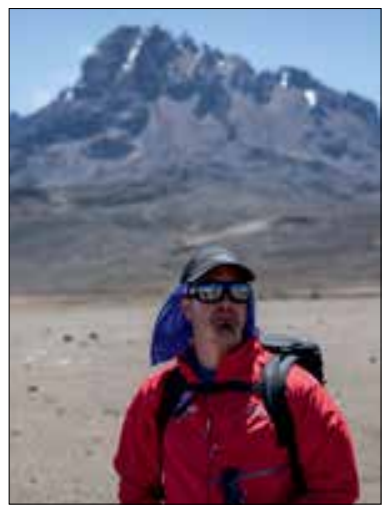

\section{Walther Meyer}

WildMedix, and Venture Forth International, Cape Town, South Africa

Mike James

Department of Anaesthesia and Perioperative Medicine, Faculty of Health Sciences, University of Cape Town, South Africa

\section{Rik De Decker}

Division of Paediatric Cardiology, University of Cape Town, and Red Cross War Memorial Children's Hospital, Cape Town, South Africa; and International Commission for Alpine Rescue, Kloten, Switzerland

Corresponding author: R Hofmeyr (ross.hofmeyr@uct.ac.za)

South African rally driver Gugu Zulu dies on Kilimanjaro. BBC News Online, 18 July 2016. http://www. bccom/news/world-africa-36823937 (accessed 10 August 2016).

2. Karinen H, Peltonen J, Tikkanen H. Prevalence of acute mountain sickness among Finnish trekkers on Mount Kilimanjaro, Tanzania: An observational study. High Alt Med Biol 2008;9(4):301-306. DOI:10.1089/ham.2008.1008

Davies AJ, Kalson NS, Stokes S, et al. Determinants of summiting success and acute mountain sickness on Mt Kilimanjaro (5 895 m). Wilderness Environ Med 2009;20(4):311-317. DOI:10.1580/1080-6032-020.004.0311 4. Jackson SJ, Varley J, Sellers C, et al. Incidence and predictors of acute mountain sickness among trekkers on Mount Kilimanjaro. High Alt Med Biol 2010;11(3):217-222. DOI:10.1089/ham.2010.1003

5. Shah NM, Windsor JS, Meijer H, Hillebrandt D. Are UK commercial expeditions complying with wilderness medical society guidelines on ascent rates to altitude? J Travel Med 2011;18(3):214-216. DOI:10.1111/j.1708-8305.2011.00511.x

6. James MF, Hofmeyr R, Grocott MP. Losing concentration: Time for a new MAPP? Br J Aneasth 2015:115(6):824-826. DOI:10.1093/bja/aev151

Gallagher SA, Hackett PH. High-altitude illness. Emerg Med Clin North Am 2004:22(2):329-355. DOI:10.1016/j.emc.2004.02.001

Hackett PH, Roach RC. High-altitude illness. N Engl I Med 2001;345(2):107-114. DOI:10.1056/ Hackett PH, Roach RC.

NEJM200107123450206
9rocott MP, Martin DS, Levett DZ, et al. Arterial blood gases and oxygen content in climbers on Mount Grocott MP, Martin DS, Levett DZ, et al. Arterial blood gases and oxygen con
Everest. N Engl J Med 2009;360(2):140-149. DOI:10.1056/NEJMoa0801581

10. Luks AM, McIntosh SE, Grissom CK, et al. Wilderness Medical Society practice guidelines for the prevention and treatment of acute altitude illness: 2014 update. Wilderness Environ Med 2014;25(4 Suppl):S4-S14. DOI:10.1016/j.wem.2014.06.017

11. Imray C, Wright A, Subudhi A, Roach R. Acute mountain sickness: Pathophysiology, prevention, and treatment. Prog Cardiovasc Dis 2010;52(6):467-484. DOI:10.1016/j.pcad.2010.02.003

12. Roach R, Bartsch P, Hackett PH, Oelz O. The Lake Louise acute mountain sickness scoring system. In: Wood S, Roach RC, eds. Hypoxia and Molecular Medicine. Burlington, VT: Queen City Printers, 1993:272-274.

3. Imray $\mathrm{CH}$, Grocott MP, Wilson MH, Hughes A, Auerbach PS. Extreme, expedition, and wilderness medicine. Lancet 2015;386(10012):2520-2525. DOI:10.1016/S0140-6736(15)01165-4

14. Wilderness Medical Society. Fellowship in the Acadamy of Wilderness Medicine 2016. http://www. wms.org/fawm/ (accessed 10 August 2016).

15. International Climbing and Mountaineering Federation/International Commission for Alpine Rescue/ International Society for Mountain Medicine. UIAA Diploma in Mountain Medicine 2016. http:// heuia.org/mountain-medicine-diploma.html (accessed 10 August 2016).

16. Mellor A, Dodds N, Joshi R, et al. Faculty of Prehospital Care, Royal College of Surgeons Edinburgh guidance for medical provision for wilderness medicine. Extrem Physiol Med 2015;4(1):22. DOI:10.1186/s13728-015-0041-x

17. Kupper T, Nies I, Jillebrandt D, Milledge JS, Basnayt B. Official Standards of the UIAA Medical Commission, vol. 8: Model Contract for Health Care on Trekking and Expeditions for Doctors. Bern, Switzerland: International Mountaineering and Climbing Federation (UIAA), 2008:8.

S Afr Med J 2016;106(9):834-835. DOI:10.7196/SAMJ.2016.v106i9.11389 